\title{
Neurophysiology of Aggression in Posttraumatic Stress Disorder
}

\section{Stanley E Smerin ${ }^{1 *}$, Aiqin $\mathrm{Chen}^{2}$ and $\mathrm{He} \mathrm{Li}^{{ }^{*}}$}

${ }^{1}$ Department of Psychiatry and Center for the Study of Traumatic Stress, Uniformed Services University of the Health Sciences, USA

${ }^{2}$ Department of Physiology and Pathophysiology; and Research Center of Neurobiology, Fujian Medical University, China

\begin{abstract}
Posttraumatic stress disorder (PTSD) is a universal anxiety disorder, affecting not only soldiers but also victims of every sort of traumatic stress-natural disaster, automobile collision, crime, domestic violence, bereavement. Aggressiveness, stemming from "intermittent explosive anger", is a not infrequent comorbidity of PTSD, with the most serious consequences. The neurophysiology of aggression and anger in general, and PTSD in particular, is a jigsaw puzzle of which we are first gathering the pieces. In this chapter, PTSD is conceptualized as revolving around an idée fix of the traumatic experience, leading to fear and a derivative defensive form of aggression. The history of research in the neurophysiology of aggression and pertinent forms of memory and emotion are then reviewed, leading to a neuronal system that spans the brain. Some basic phenomena in neurophysiology are touched onsynaptic plasticity in the form of long-term potentiation of synaptic transmission, G-protein-coupled receptor modulation thereof, and the theta rhythm of the electroencephalogram-and the path we are following in our attempt to integrate these phenomena into a model of the neurophysiology of aggression in PTSD is described.
\end{abstract}

Keywords: PTSD; Posttraumatic stress disorder; Aggression; Anger; Anxiety; Hippocampus; Amygdala; Hypothalamus; Hypothalamic attack area; Prefrontal cortex; Bed nucleus of the stria terminalis; Theta rhythm; Long-term potentiation; Synaptic plasticity; G-proteincoupled receptors; Serotonin; Norepinephrine

\section{Introduction}

"Trauma destroys the fabric of time...it doesn't just destroy the flow of the present into the future; it corrodes everything that came before, eating at moments and people from your previous life, until you can't remember why any of them mattered."

\section{David J. Morris, The Evil Hours}

The conceptualization and analysis of posttraumatic stress disorder (PTSD) began in 1967 under the tutelage of Eugene Brody [1]. The two faces of PTSD are fear and anger or aggression. It was not until the release of the fifth edition of the American Psychiatric Association's Diagnostic and Statistical Manual of Mental Disorders in late 2014 that the importance of aggression in PTSD was fully acknowledged. Many clinical studies led up to this realization that aggression is major in PTSD [2-8]. A meta-analysis of 39 such studies found that aggression is a major component of PTSD [9], with severity increasing with time. There were many cases on record in which the aggression of PTSD took the form of irrational, angry attack-attack upon unprovoking civilians or even family members. A survey as part of the National Vietnam Veterans Readjustment Study showed that about one-third of veterans with PTSD perpetrated "intimate partner violence" in the previous year, nearly three times the rate of both veterans without PTSD and the general public [10]. In fact, over the last decade, PTSD has been extensively linked to violence, especially intimate partner violence, and especially in the military [11-20]. The irrational, angry attack is increasingly recognized to include suicide, angry attack of the patient against his or her own self. A large number of individuals in the United States self-report patterns of impulsive angry behavior and also possess firearms at home (8.9\%) or carry guns outside the home (1.5\%) [21]. According to the Center for Disease Control and Prevention, intentional acts of interpersonal violence with guns killed 11,622 people and injured an additional 59,077 people in the United States in 2012. Although irrational, angry attack stemming from PTSD presents an ever-increasing danger to society as more and more troops return from Iraq and Afghanistan, the neuropsychology of PTSD is not understood.

\section{The Idée Fixe and Its Context}

PTSD revolves around an idée fixe of terror. Ideas sink into the mind as they are related to other ideas. But this idea cannot be made congruent with others. Not only can it take center stage in life, but, by being always present during the normal process of memory reconsolidation [22,23], it can progressively metastasize throughout the patient's psyche. Cognitive therapy, in one sense, is a struggle to take over the idée fixe with positive memory and experience, rather than let the idée fixe reshape other memories and experience. The thesis of this chapter is that potentiation of synaptic transmission between hippocampus, prefrontal cortex, amygdala, and hypothalamus, modulated by synapses mediated by G-protein-coupled receptor, fixes the cognition of the traumatic event to the emotional response. Thereafter, when any memory is recalled in the normal or stress-altered process of memory reconsolidation, the traumatic emotional response is attached to that memory too. The psychosis is intrinsically one of the anxieties, with other manifestations such as fear, and both defensive, and impulsive aggression. The context of the terrible experience is fixed along with the experience, generalizing to all environments in which the patient is present, including otherwise obviously safe environments. This generalizing of context and the fixing of the experience to the generalized context appears to be largely a function of the hippocampus and adjacent cortex, and will be discussed further in the following text.

\section{PTSD Seen as Defensive Aggression}

The pioneering neurophysiology on aggression was done in cats, which evince a clear defensive rage in response to danger such as a

*Corresponding authors: Stanley E Smerin, Department of Psychiatry, Uniformed Services University of the Health Sciences, 4301 Jones Bridge Road, Bethesda MD 20814, USA, Tel: 3012953295; Fax: 3012951536; E-mail: stanley.smerin@ usuhs.edu

$\mathrm{He} \mathrm{Li}$, Associate Professor, Department of Psychiatry, Uniformed Services University of the Health Sciences, 4301 Jones Bridge Road, Bethesda, MD 20814, USA, Tel: 3012953295; Fax: 3012951536, E-mail: he.li@usuhs.edu

Received December 16, 2015; Accepted April 28, 2016; Published May 05, 2016

Citation: Smerin SE, Chen A, Li H (2016) Neurophysiology of Aggression in Posttraumatic Stress Disorder. J Psychiatry 19: 364 doi:10.4172/23785756.1000364

Copyright: (c) 2016 Smerin SE, et al. This is an open-access article distributed under the terms of the Creative Commons Attribution License, which permits unrestricted use, distribution, and reproduction in any medium, provided the original author and source are credited. 
menacing dog. The defensive rage consists of piloerection, pupillary dilation, sweating of the paws, growling, hissing, and ultimately either attack or escape. (Growing up in neighborhoods having dogs and feral cats, the author has witnessed such defensive attack by a cat onto the face of a dog, menacing or possibly just curious, numerous times.) We understand this defensive rage to be closely akin to the aggression of PTSD.

At this point in time, the escalation of adaptive aggression violence of PTSD can be most readily tied to three structures-the hippocampus, the amygdala, and the functionally defined "hypothalamic attack area." Attribution of attack was first focused on the hypothalamus by Bard [24] who in 1928 showed in cats that removal of the entire brain rostral to the hypothalamus left an animal capable of, and actually prone to, blind rage attacks, while if the hypothalamus was also removed then only component reflexes remained. In the cat made placid by extirpation of the entire neocortex, Bard and Mountcastle found that the only subsequent forebrain lesion that caused the gentle cat to become savage was removal of amygdala and pyriform lobe [25], leading to the inference that amygdala, or some subsystem therein, inhibits the hypothalamic attack area. With advances in electronics, it was discovered that this rage reaction could be sham elicited by electrical stimulation in central grey extending from the posterior hypothalamus to the periaqueductal grey $[26,27]$. Congruent with the lesions study of Bard and Mountcastle just mentioned [25], electrical stimulation of the basolateral amygdala concomitant with stimulation of the hypothalamus suppressed the attack that would otherwise result from the hypothalamic stimulation $[28,29]$.

\section{Rodent Model for Research on PTSD}

In subsequent research, aggression in rodents has been favored over the cats because rodents are more manageable in behavioral testing, have the same basic defensive aggression, the same basic neuronal structure, and, especially in the case of the mouse, have been extensively developed for genetic manipulation. In our own rat model of PTSD, a number of signal pathways have been found to coactivate with the acoustic startle response pathognomonic of PTSD [30], and corticosterone was found to mitigate the acoustic startle response [31]. Signs of defensive aggression in the rat, in addition to attack, are much the same as in the cat-piloerection, sweating of the paws, and ultimately attack or escape. While hissing and growling are not audible to humans, such signs are being sought in recordings of the ultra-high frequency vocalization of the rat. Defensive aggression in the rat and mouse has been most studied in the "resident-intruder" paradigm [32,33], in which a male rodent resident in a cage, cohabiting with a female, attacks another rodent that intrudes in the resident's domain. In mimicking PTSD per sé in an animal model, Siegmund and Wotjak [34] distinguished two components that can be addressed in a rodent model of PTSD-memory and sensitization, which have been largely localized to the hippocampus and amygdala, respectively.

\section{The Amygdala, Hypothalamic Attack Area, and Hippocampus}

Recent research, mostly in the rat, has confirmed and detailed the classic behavioral neurophysiology described previously in the cat. The influence of the basal amygdala, medial amygdala, septum, and bed nucleus of the stria terminalis specifically are seen to influence the hypothalamic attack area. Neurostimulation behavior experiments $[35,36]$ have resolved the hypothalamic attack area to the anterior hypothalamic nucleus, the dorsomedial and ventrolateral divisions of the ventromedial hypothalamus, and the nearly coextensive rostral level of the lateral and dorsolateral columns of the periaqueductal gray [37]. The impulsivity of the attack, the absence of preliminaries, the insensitivity for context, the absence of aims resulting from electrical stimulation therein suggest that the hypothalamic attack area itself functions merely to destroy [38], requiring rostral regions of the brain to control and direct its function.

The amygdala is composed of subnuclei, each having their own network. The lateral amygdala brings in auditory information from the medial geniculate, spatial structure, and memory from the hippocampal formation and temporal cortex, and forwards that to the basal amygdala for some level of processing. The basal amygdala connects to the central amygdala and the medial amygdala.

The central amygdala ties in with the autonomic nervous system. c-Fos, a protein indicative of cellular activation, is consistently expressed in the central amygdala of both rat and mouse in the resident-intruder paradigm, and decreased in the lateral septum [39]. Optogenetic stimulation of lateral basal amygdala terminals in the central amygdala is anxiolytic [40].

The medial amygdala projects heavily and specifically to the anterior and ventromedial hypothalamic nuclei [41]. The projection from the medial amygdala to the hypothalamus corresponds to the hypothalamic attack area [42]. Likewise, cells in the floor of the hypothalamus that reciprocally project to the medial amygdala are located in a continuous layer in the floor of the hypothalamus. c-Fos is increased in the medial amygdala, as well as the hypothalamic attack area, of rats [43] and mice [44] after the resident-intruder paradigm activation. Although the majority of neurons of the medial amygdala are striatum like GABAergic medium spiny neurons, the majority of medial amygdala neurons projecting to the ventromedial hypothalamus are cortical like glutamatergic pyramidal neurons receiving excitatory input from sensory neurons and inhibition from local GABAergic neurons [45]. Therefore, it might be expected that the medial amygdala would promote aggression. Congruently, lesions in the medial amygdala reduce defensive aggression in the rat [46].

However, the internal function of even a part of the medial amygdala, the posterodorsal subnucleus, creates a balance, because GABAergic neurons therein promote aggression and glutamatergic neurons inhibit aggression [47]. Since GABAergic neurons, which are inhibitory, are promoting aggression and glutamatergic neurons, which are excitatory, are inhibiting aggression, it must be recognized that there must be an alternation between excitation and inhibition before the final result, attack, is produced. This alternation is to be researched in the alluvial fan spreading out from the medial amygdala to include the hypothalamic attack area. This alluvial fan includes the bed nucleus of the stria terminalis and the septum. As well as projecting to the hypothalamic attack area directly, the medial amygdala projects topographically and reciprocally to the bed nucleus of the stria terminalis $[48,49]$. c-Fos is increased in the bed nucleus of the stria terminalis, as well as the medial amygdala and hypothalamic attack area, of rats [43] and mice [44] after the resident-intruder paradigm activation. Projections from the lateral septum frequently converge with amygdala afferents onto medial hypothalamic neurons [40,50]. Stimulation of lateral septum in the rat suppresses aggressiveness [51]. The posterior division of the bed nucleus of the stria terminalis has its own network domain, with some of the projections from the interfascicular and transverse divisions of the bed nucleus of the stria terminalis continuing to the hypothalamic attack area [49]. 
Along with the medial amygdala, bed nucleus of the stria terminalis, and septum, the amygdalohippocampal area and the subiculum project to the hypothalamic attack area, as does a plate containing the orbitofrontal, medial prefrontal [40]. The hypothesis that context memory subserved by the hippocampal formation subserves context memory in PTSD, explained later, is supported by the demonstration of reciprocal connections between the medial amygdala and the amygdalohippocampal area on one side, and the ventrolateral part of the ventromedial hypothalamus on the other side [52]. In addition, the amygdalohippocampal area massively innervates the bed nucleus of the stria terminalis, the lateral septal nucleus, the cingulate cortex, and the prefrontal cortex [53], further tying the hippocampus and memory in with the basal forebrain system of aggression just described.

\section{The Amygdala in PTSD}

Lesion studies in the rat show that the amygdala is involved in aggression [54]. Optogenetic stimulation in the amygdala generates anxiety in mice [55]. Fear conditioning induces long-term potentiation of synaptic transmission in the lateral [56,57] and basolateral [58] amygdala of the rat. The amygdala may be understood as associating the visceral and somatic components of fight/flight to hippocampalentorhinal-prefrontal cortical representation of environment. The resultant state is anxiety, and in the extreme, PTSD, with various manifestations as fear, aggression, and avoidance.

\section{The Amygdala and Hippocampus in PTSD}

Memory per sé is a function of the hippocampus [59], to the exclusion of the amygdala. In humans with congenital progressive destruction of the basolateral amygdala, working memory is intact, even facilitated [60]. Numerous studies of memory in rats, reviewed by Squire [61], confirm this finding. So, the amygdala is not a memory processor per sé. But the amygdala appears to participate in the stressinduced consolidation of memory in that lesion or inactivation of the amygdala blocks stress-induced impairment of hippocampal long-term potentiation and spatial memory [62].

The idée fixe may be broken down into the traumatic event and the context of that event. In rodent models of PTSD, the relevant aspect of memory reverberating between the hippocampus and the amygdala is the context of traumatic experience [63].The hippocampus is involved in the long-term, ongoing reconsolidation of this context memory as well as the initial consolidation [64]. The amygdala appears to participate with the hippocampus in this process [62]. PTSD patients show a globally diminished capacity to use contextual memory to modulate fear expression [65], which may underlie the anxiety experienced by PTSD patients in even safe environments far from their traumatic experience. Memory of context subsumed by "place" cells in the hippocampus [66] and "grid" cells in the entorhinal cortex $[67,68]$ is, to date, one of the most extensively worked out systems in the brain. Cues may represent the event and are evidenced to alter the context map [69].

Vulnerability to PTSD and the paranoia underlying PTSD then may be understood as an ability of the amygdala in those individuals to associate the visceral and somatic components of fight/flight to hippocampal-entorhinal-prefrontal cortical representation of all environments, and to do so permanently. Alternatively, the vulnerability may be an inability of perhaps the hippocampal-entorhinal-prefrontal cortices to constrain the indiscriminant association of the visceral and somatic components of fight/flight to all representations of experience. The objective of neurophysiologic research in our laboratory at the
Center for the Study of Traumatic Stress at the Uniformed Services University is to understand the neurophysiology of this vulnerability.

\section{The Theta Rhythm and Context Memory}

The $4-12 \mathrm{~Hz}$ theta rhythm, a semi-sinusoidal fluctuation in the electric field of the brain most readily recorded in the hippocampus [70], is the manifestation of a process that is intrinsic to the mapping of space and cognition in the hippocampal formation. Whether the hippocampal theta rhythm is induced locally [71,72], from the lateral basal amygdala [73], from the septum [74], from dorsal raphé serotonergic projections [75], from the supramammilary nucleus of the hypothalamus [76], from nucleus reticularis pontis oralis $[77,78]$, or from all six, theta phase appears to be mechanistically involved in spatial coding in both the hippocampus [79] and the medial entorhinal cortex [80]. Theta paces the updating of cue-referenced context maps in the CA3 hippocampus [81]. Consequently, loss of hippocampal theta rhythm results in context memory deficit [82], which, as indicated earlier, is part of PTSD. During anxiety behavior in mice, the synchrony of the theta rhythm in the ventral hippocampus and the medial prefrontal cortex increases [83]. High-frequency gamma oscillations synchronize with the theta rhythm [84]; these may be a manifestation of the actual information transmitted among CA1, CA3, medial entorhinal cortex, and possibly other brain regions during each theta cycle.

\section{The Theta Rhythm and Synaptic Potentiation}

Hippocampal excitability is phase-locked to the theta rhythm in free-moving rats [85]. Stimulation at the theta frequency is optimal for the induction of hippocampal long-term potentiation of synaptic transmission [86]. High-frequency electrical stimulation in hippocampal CA1 in behaving rats yields long-term potentiation of synaptic transmission when delivered to the peak of theta and longterm depression when delivered to the trough [87]. High-frequency electrical stimulation to perforant path between hippocampus CA1 and entorhinal cortex in urethane-anesthetized rats yields longterm potentiation when delivered to the peak of theta and long-term depression when delivered to the trough [88].

In addition to the previously mentioned brain regions, hippocampal theta synchronizes with the dorsal raphé nucleus. The discharge of half of the neurons in the dorsal raphé nucleus synchronizes with hippocampal theta. The electrophysiology of these dorsal raphé neurons suggests that they are the serotonergic pool composing half of the population in the dorsal raphé nucleus [89].

In our own laboratory, high-frequency packets of electrical stimulation given at the theta frequency to the lateral basal amygdala in the in vitro slice of the rat's brain induces short-term potentiation; when two such theta burst stimulations are given ten minutes apart, longterm potentiation is induced [90]. That high-frequency stimulation of the ventral angular bundle, which projects from hippocampus to lateral basal amygdala, induces long-term potentiation of synaptic transmission in the lateral basal amygdala is particularly significant in PTSD research in that lesion of ventral angular bundle blocks fear conditioning to context [91]. Synaptic potentiation and the amygdala are therein connected to fear of environment and resultant defensive aggression in PTSD.

\section{Synaptic G-Protein-Coupled Receptors Are the Key}

The G-protein-coupled receptors in synaptic transmission are the key in deciphering the neurophysiology of aggression in PTSD, because the neurotransmitters for these-serotonin, norepinephrine, 
acetylcholine, and vasopressin, among others-modulate aggressiveness in animal models, regulate the theta rhythm, prime the induction of long-term potentiation of synaptic transmission, and, in the case of serotonin and norepinephrine together, have been found to be therapeutic for aggression in PTSD.

Serotonin, with its receptors, is widely studied in anxiety [92] and is the most widely studied neurochemical in relation to aggression [93]. Increase of serotonin in the midbrain [94], as well as stimulation of serotonergic neurons in the dorsal raphé nucleus, causing release of serotonin in the medial prefrontal cortex among other locations [95], escalates intermale aggression in mice in the resident-intruder paradigm. Serotonin appears to act by increasing the intensity of the aggression, rather than by decreasing the threshold for the aggression [94]. Paradoxically, aggression toward a human intruder is increased with blockade of the $5-\mathrm{HT}_{1 \mathrm{~A}}$ receptor in normal rats, and $5-\mathrm{HT}_{1 \mathrm{~A}}$ receptor expression is decreased in frontal cortex, amygdala, hypothalamus, and midbrain in rats bred for aggressiveness toward a human intruder [96]. Likewise, rats bred for aggressiveness toward a human intruder have decreased levels of serotonin in the hypothalamus, midbrain, and cortices relative to rats bred for low aggressiveness toward a human intruder [97]. Resolution of the paradox may be found in perhaps two ways. First, serotonin may promote aggression by acting on a serotonin receptor other than the $5-\mathrm{HT}_{1 \mathrm{~A}}$ receptor, perhaps the $5-\mathrm{HT}_{2 \mathrm{~A}}$ receptor. Indeed, in our learned helplessness in rat model of PTSD, it is an antagonist for the serotonin $5-\mathrm{HT}_{2 \mathrm{~A}}$ receptor (MDL 11,939) that prevents exaggeration of the acoustic startle response pathognomonic for PTSD [98]. Second, the resident-intruder paradigm may, after all, measure a dominance-based offensive aggression against a conspecific, while the paradigm based on aggression toward a human intruder, menacing by sheer size, measures defensive aggression. Rats bred for aggressiveness in this "human-intruder" paradigm were, in fact, not more aggressive toward conspecifics in the resident-intruder paradigm [97]. The human-intruder paradigm would best parallel the situation producing the defensive aggression of PTSD. Importantly, in this human-intruder paradigm, it is a decrease, rather than an increase, in serotonergic transmission that leads to the defensive aggression of PTSD. Therapy for aggression in PTSD based on increasing serotonin is then congruent.

A dorsal raphé nucleus serotonergic projection to hippocampus generates theta rhythm [75]. $\mathrm{GABA}_{\mathrm{B}}$ receptors in the dorsal raphé nucleus activate these serotonergic neurons, and, after ethanol ingestion, a major comorbidity of PTSD, GABA ${ }_{A}$ receptors are activating too [99]. The GABA receptors are not on the serotonergic neuron itself, so must be on some interneuron or presynaptic terminal in the dorsal raphé nucleus [100]. Similarly, the GABA receptors are not on the serotonergic neuron itself in the lateral amygdala [101]. Stress, in our rat model of PTSD, blocks the facilitation of induction of long-term potentiation of synaptic transmission by a serotonin $5-\mathrm{HT}_{2}$ receptor agonist (DOI) in the lateral amygdala [102], indicating that stress decreases the expression of the serotonin $5-\mathrm{HT}_{2}$ receptors that mediate the facilitation of induction of long-term potentiation in the lateral amygdala. Stimulation of the medial prefrontal cortex reciprocal projections back to the dorsal raphé nucleus increases effort by a rat [103], which may correspond to the impulsivity of PTSD. Activation is seen in the medial prefrontal cortex of soldiers with PTSD when hearing recorded sounds of battle [104].

Norepinephrine is important in PTSD. In our rat model of PTSD, the norepinephrine alpha 1 receptor agonist, A61603, diminishes anxiety and fear, as measured by the acoustic startle response [105], an indicator of hyper arousal, anxiety, fear, and likely aggressiveness in PTSD. So, the action of norepinephrine via its alpha 1 receptor in diminishing anxiety symptoms may be via blockade of potentiation of excitatory synaptic transmission. Norepinephrine may diminish anxiety symptoms by blocking facilitation of excitatory synaptic transmission, as expanded upon below, or by facilitating the release of the inhibitory neurotransmitter GABA. In our rat model of PTSD, the same norepinephrine alpha 1 receptor agonist, A61603, facilitates GABAergic neurotransmission in the lateral amygdala, and stress impairs that facilitation [106].

Venlafaxine, a serotonin-norepinephrine reuptake inhibitor, increases both serotonin- and norepinephrine-mediated neurotransmission. Venlafaxine is the only medication to date to show direct improvements in PTSD patients' ability to deal with daily stress, anger, and aggression $[107,108]$, indicating that, as inferred earlier, a combined increase in both serotonin- and norepinephrine-mediated neurotransmission diminishes the defensive aggression of PTSD. The aggressiveness is decreased by venlafaxine before fear cognition is decreased [107], suggesting that it is the connection between the hippocampal formation and the amygdala that is blocked.

As stated earlier, serotonergic neurons in the dorsal raphé nucleus synchronize with hippocampal theta [89]. Inhibition of serotonergic neurons in the medial raphé nucleus increases hippocampal theta, indicating that serotonergic neurons in the medial raphé nucleus normally decrease hippocampal theta [109]. Serotonin, acting via its $5-\mathrm{HT}_{2 \mathrm{~A}}$ receptor, primes the induction of long-term potentiation in the lateral basal amygdala slice such that long-term potentiation requires only a single, rather than a double, theta burst stimulation to induce long-term potentiation [110]. Additionally, stress impairs 5- $\mathrm{HT}_{2 \mathrm{~A}}$ receptor-mediated serotonergic facilitation of GABA release in the lateral amygdala [101]. So a model is emerging in which serotonin $5-\mathrm{HT}_{2 \mathrm{~A}}$ receptor-mediated enhancement of long-term potentiation and GABA release damps anger and acts as a brake on aggression. Stress-induced diminution of this serotonergic transmission promotes defensive aggression. Enhancement of the serotonergic transmission is therapeutic. The model includes alpha 1 receptor-mediated noradrenergic transmission in the same way.

Cholinergic projections that act on muscarinic receptors, a G-protein-coupled receptor, on principle neurons in the entorhinal cortex and in the lateral amygdala generate persistent, graded activity. For the lateral amygdala, these cholinergic projections are demonstrated to be from the basal nucleus of Meynert [111]. Muscarinic cholinergic synapses influence septal-hippocampal theta [112].

Increase of vasopressin, which is a G-protein-coupled receptor ligand [113], in the lateral septum correlates with increased resident aggression against an intruder, while increase of vasopressin in the bed nucleus of the stria terminalis correlates with decreased resident aggression against an intruder [114]. The vasopressin $1 \mathrm{~b}$ receptor, one of the two principle vasopressin receptors in the brain mediating behavior, has its major expression in the hippocampus, specifically in the limited CA2 region [115]. Vasopressin perfusion into the medial amygdala is antipyretic [116], suggesting systemic deactivation since pyresis is a result of energy production.

While most examples of priming induction of long-term potentiation are direct (monosynaptic) as in the case of the projection from the hippocampus to the lateral basal amygdala [91], priming of the induction of long-term potentiation can also have multiple stages and more than one G-protein-coupled receptor synapses involved. An 
example is the following pathway: nucleus subcoeruleus-acetylcholine $\rightarrow$ nucleus locus coeruleus-norepinephrine $\rightarrow$ septum $\rightarrow$ dentate gyrus, which ultimately primes long-term potentiation in the perforant path to dentate granule cell synapse [117].

\section{Genomics of Aggressiveness in PTSD}

Along with the aggressiveness of PTSD and the hypothesized alteration of neuroplasticity in the hippocampus, amygdala, and prefrontal cortex, evidence is appearing for dysregulation of gene expression. Two hundred twenty five (225) mitochondrial related genes in the amygdala and 295 mitochondrial related genes in the prefrontal cortex of the male rat are dysregulated in response to tail-shock stress [30]. Three (3) of the stress dysregulated mitochondrial related genes in the amygdala - Elk3, Avp, Bcl2l1 - and four (4) in the prefrontal cortex - AVP, PrkcdbP, AZin1, Srf - are also found in the set of 105 genes up or down regulated in association with territorial aggressiveness [118]. The inference then is that stress dysregulation of gene expression promotes aggressiveness. The AVP gene is particularly relevant in that the metabolic product - arginine vasopressin - is central to stress induced aggressiveness [114] and is a G-protein receptor ligand such as is here hypothesized to be instrumental in neuroplasticity underlying aggression.

In the female rat, similarly, gene dysregulation is associated with aggressiveness. In the female rat 400 genes in the amygdala and 368 genes in the hippocampus are dysregulated in response to predator odor stress [119]. Four (4) of these stress dysregulated genes in the amygdala AKt1, Avp, Fos, Oaz1 - and three (3) in the hippocampus - Akt1, Tcf4, FOS - are also found in the set of 105 genes up or down regulated in association with territorial aggressiveness [118]. The inference then is that stress dysregulation of gene expression promotes aggressiveness in females as well as males.

Since post-traumatic stress disorder significantly increases risk for suicide, even after adjusting for depression, which is often comorbid, it is noteworthy that three genes correlated with suicide - TUBA1, CTSD, and Grik 2 - are dysregulated by stress in the tail-shock rat model of PTSD [30]. The genomics of PTSD are similar in the mouse [120].

\section{The Neuronal System in Aggression}

The Figure 1 represents the neuronal structures and interactions.

How these structures interact in anxiety, aggression, and fear is for the most part not known. One technique for finding out is to measure the synaptic connectivity within and between these brain nuclei with the electrically evoked excitatory postsynaptic field potential during the escalation leading up to aggression. The excitatory postsynaptic field potential, measured with a metal electrode inserted into the nucleus under stereotaxic guidance, is a waveform graphing the activation of the whole population of excitatory synapses over time evoked by electrical stimulation through another electrode. The baseline stimulation is given as single pulse at a low frequency, perhaps one pulse every ten seconds, so that the response to the pulses is far enough apart in time to not interact with each other. Giving a brief burst of stimulation pulses at a high frequency, say 100 pulses per second for five seconds, can reveal an ability of the synapses to be "potentiated," that is, after the stimulation is returned to the slow, baseline rate, the amplitude of the field potential is observed to be larger. Figure 2 is an example of an excitatory postsynaptic field potential evoked in the amydalohippocampal area by electrical stimulation of the medial amygdala in a (urethane-anesthetized) rat. The two traces at the upper left are the time course of an excitatory postsynaptic field potential

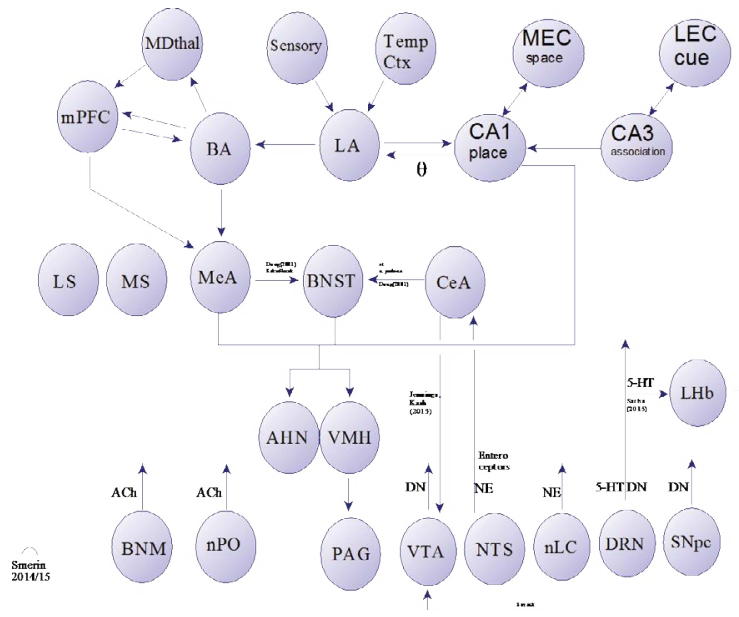

Figure 1: Neuronal structures involved in aggression, and their connectivity: AHN: anterior hypothalamic nucleus; BA: basal amygdala; BNM: basal nucleus of Meynert; BNST: bed nucleus of the stria terminalis; CA1: cornu Ammonis (Latin for Ammon's horn, another name for the hippocampus) area 1; CA3: cornu Ammonis area 3; CeA: central nucleus of the amygdala; DRN: dorsal raphé nucleus; LA: lateral amygdala; LEC: lateral entorhinal cortex; LHb: lateral habenula; LS: lateral septum; MDThal: dorsomedial thalamus; MeA: medial amygdala; MEC: medial entorhinal cortex; mPFC: medial prefrontal cortex; MS: medial septum; nLC: nucleus locus coeruleus; nPO: nucleus pontis oralis; NTS: nucleus tractus solitarius; PAG: periaqueductal grey; Sensory: mainly auditory, inputs to lateral amygdala; SNpc: substantia nigra pars compacta; Temp Ctx: temporal cortex; VTA: ventral tegmental area; $\mathrm{VMH}$ : ventromedial hypothalamus; $\mathrm{ACh}$ : acetylcholine; $\mathrm{NE}$ : norepinephrine; 5-HT: serotonin; DN: dopamine.

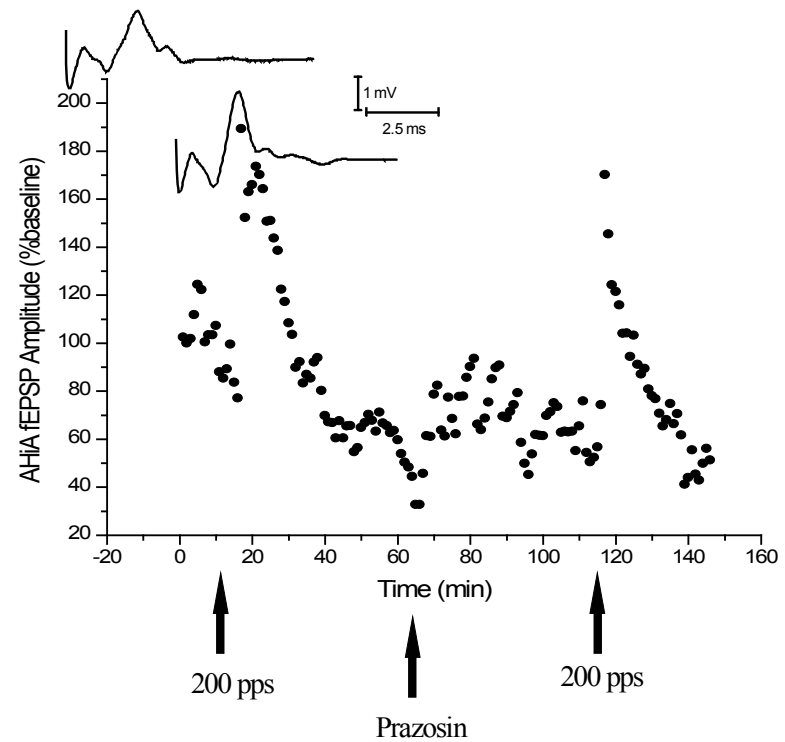

Figure 2: Excitatory postsynaptic field potential (fEPSP) in the amygdalohippocampal area $(\mathrm{AHiA})$ of an (anesthetized) rat evoked by electrical stimulation of the medial amygdala. (See text for description).

generated by the medial amygdala synapses on all of the neurons in the amygdalohippocampal area around the recording electrode. The upper 
trace is before a burst of high-frequency stimulation was given through the stimulating electrode in the medial amygdala, and the second trace, visibly larger, was recorded after the high-frequency burst. Each point in the graph represents the average of the maximum amplitude of six excitatory postsynaptic field potentials. The excitatory postsynaptic field potential is seen to increase after high-frequency stimulation (200 pulses per second in this case). Prazosin, a norepinephrine receptor antagonist that is therapeutic (for the sleep disturbance) in PTSD, diminishes the increase following high-frequency stimulation.

Because it connects the theta rhythm to synaptic potentiation, a technique for studying the two together employed in our lab is the "two theta burst/long-term potentiation" paradigm [121]. In the in vitro brain slice from the rat containing the basolateral amygdala a single "theta burst" induces "short-term potentiation," and two theta bursts delivered ten minutes apart induce long-term potentiation. Shortterm potentiation is an increase in the efficacy of the transmission at the synapse which lasts a few minutes. Long-term potentiation is an increase in the efficacy of the transmission at the synapse which lasts as long as the tissue remains healthy in the case of the brain slice in vitro and for hours to days or more in the living organism. The stimulation inducing this potentiation of synaptic transmission is given at the theta frequency, about $5 \mathrm{~Hz}$. More specifically, packets of electrical pulses are given at five packets per second, each packet consisting of highfrequency pulses at 100 pulses per second. The high frequency in each packet matches the Gamma frequency mentioned earlier which is contained within the theta frequency (Figure 3).

A1: Excitatory postsynaptic field potentials (fEPSPs) recorded before (a), after (b) and 30 minutes after (c) theta burst stimulation to the external capsule (EC), an axonal bundle that contains medial geniculate auditory afferents to the lateral amygdala. Each of these fEPSPs is evoked by a single electrical pulse delivered to the external capsule. These probe pulses are delivered ten minutes apart, far enough apart in time so that the fEPSPs they evoke do not interact. A2: Time series of the amplitudes of the fEPSPs. Each point is first an average of six fEPSPs from a single brain slice, then averaged over six slices, with error bars shown. In the control condition, first theta burst stimulation induces short-term potentiation and a second theta burst stimulation delivered ten minutes later induces long-term potentiation. The glutamatergic NMDA receptor blocker APV blocks synaptic potentiation, showing that the potentiation is dependent on release of the transmitter glutamate at the synapse and its action on the NMDA receptor. $\mathrm{B}$ : The same as $\mathrm{A}$, with the addition of recordings in which theta burst stimulation was given to the ventrobasal amygdala (VBA), instead of the external capsule. Theta burst stimulation to the VBA induces no potentiation of synaptic transmission in the basolateral amygdala. This negative result is important because it shows that the two theta burst technique can differentiate functionally connected regions from those that are not. (See text for further explanation.)

G-protein-coupled receptor-mediated synaptic transmission can have an equivalent effect to the second theta burst in inducing longterm potentiation of synaptic transmission. An example is shown in Figure 4 in which the brain slice in vitro taken from the rat at the level of the amygdala is exposed to a serotonin $5-\mathrm{HT}_{2 \mathrm{~A}}$ receptor agonist (DOI). In the presence of the serotonin agonist, just one theta burst is sufficient to induce long-term potentiation of synaptic transmission in the lateral amygdala, indicating that modulation by serotonergic synapses primes long-term potentiation of synaptic transmission. In vivo, an antagonist for the serotonin 5- $\mathrm{HT}_{2 \mathrm{~A}}$ receptor (MDL 11,939) prevents exaggeration of the acoustic startle response in our rat model of PTSD [98].
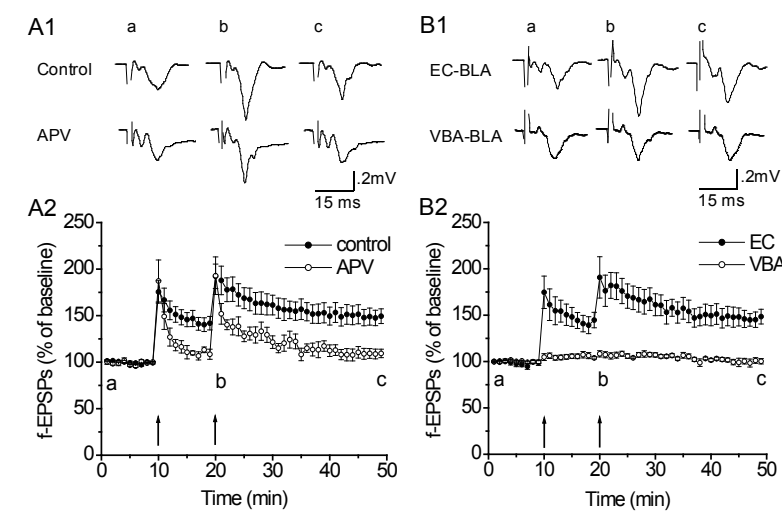

Figure 3: Two theta bursts-induced long-term potentiation in the lateral amygdala in the in vitro brain slice of the rat.

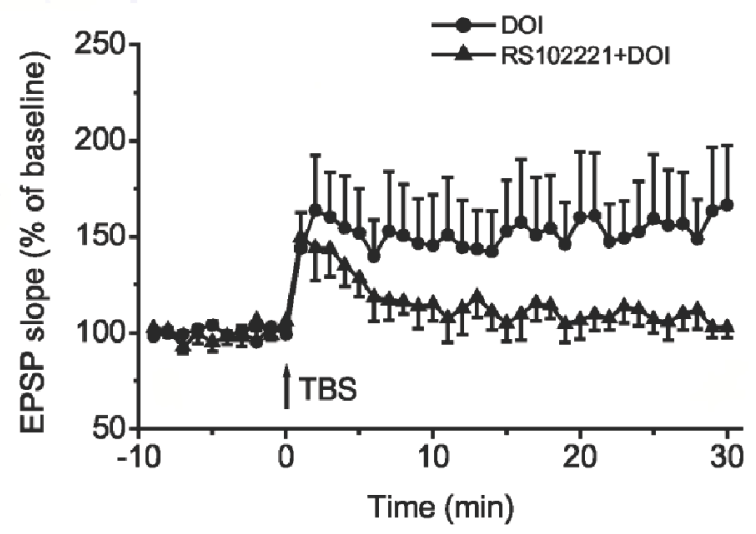

Figure 4: The serotonin $5-\mathrm{HT}_{2 \mathrm{~A}}$ receptor agonist (DOI) primes theta burstinduced long-term potentiation of synaptic transmission in the lateral amygdala.

The conditions are the same as in Figure 3. In the electrophysiology graphed in Figure 4, the serotonin $5-\mathrm{HT}_{2 \mathrm{~A}}$ receptor agonist DOI is present in the slice bath, either alone or with the serotonin $5-\mathrm{HT}_{2 \mathrm{~A}}$ receptor blocker RS 102221. In the presence of the serotonin 5- $\mathrm{HT}_{2 \mathrm{~A}}$ receptor agonist, a single theta burst is sufficient to induce long-term potentiation of synaptic transmission. Serotonin modulation can now be understood to be equivalent to, or a proxy for, theta frequency stimulation. Blocking the influence of serotonin blocks the induction of long-term potentiation of synaptic transmission.

Alternatively, G-protein-coupled receptor-mediated synaptic transmission can block long-term potentiation that would otherwise be induced by two theta bursts. An example is shown in Figure 5 in which the brain slice in vitro taken from the rat at the level of the amygdala is exposed to a norepinephrine alpha 1 receptor agonist (A61603). In the presence of the norepinephrine agonist, two theta bursts separated by ten minutes fail to induce long-term potentiation in the lateral amygdala.

The conditions are the same as in Figure 3. In the electrophysiology graphed in Figure 5, when the norepinephrine alpha 1 receptor agonist 


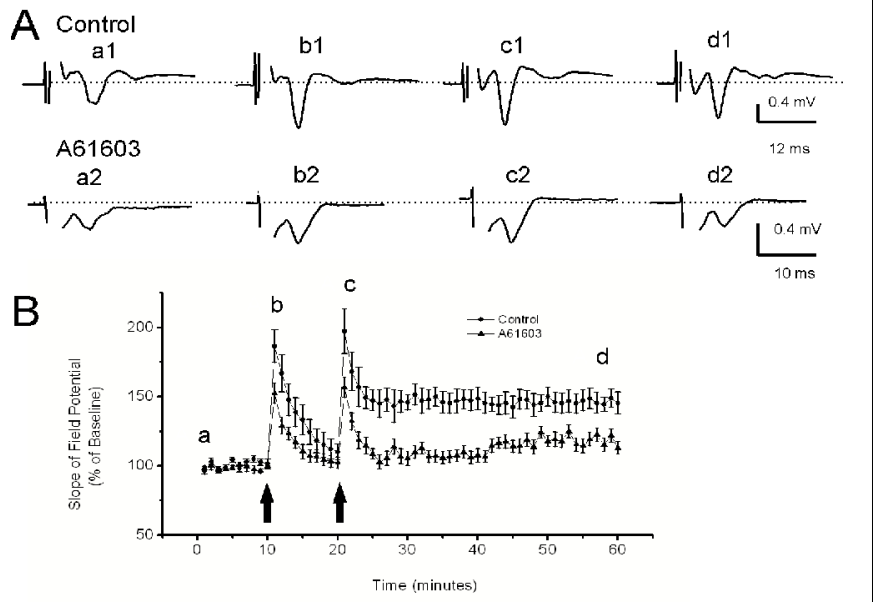

Figure 5: The norepinephrine alpha 1 receptor agonist (A61603) blocks two theta burst-induced long-term potentiation of synaptic transmission in the lateral amygdala.

(A61603) is present in the slice bath, two theta bursts fail to induce longterm potentiation. Norepinephrine modulation can now be understood to counter theta frequency-induced synaptic potentiation

In our rat model of PTSD, the same norepinephrine alpha 1 receptor agonist, A61603, diminishes hyper arousal, as measured by the acoustic startle response [105]. Hyper arousal is symptomatic of PTSD. So, the action of norepinephrine via its alpha 1 receptor in diminishing PTSD-like symptoms may be via blockade of potentiation of excitatory synaptic transmission.

Mechanistically similar results in synaptic transmission have been found in the bed nucleus of the stria terminalis with dopamine D1 receptors [122] and the vasopressin receptor.

To recapitulate the main points, a burst of stimulation at a frequency matching the endogenous theta frequency of the electroencephalogram, given in the in vitro brain slice, potentiates synaptic transmission for a short time, a few minutes. A second theta burst given ten minutes later extends that synaptic potentiation to the long term. This paradigm shows a functional connection between brain regions in that not all brain regions respond. As examples of modulation of synaptic potentiation in one synapse by $\mathrm{G}$ protein-receptor-coupled synaptic transmission at another synapse, serotonergic transmission can transform theta burstinduced short-term potentiation of synaptic transmission to long-term potentiation, and noradrenergic transmission can block long-term potentiation. At least via some of their receptors, the effect of serotonin and norepinephrine on synaptic potentiation appears to correspond to their effect on anxiety symptoms.

\section{Discussion and Conclusion}

\section{Current Work}

To better understand and treat aggressiveness in PTSD, current work in the behavioral neurophysiology laboratory at the Center for the Study of Traumatic Stress is bringing together clinical analysis of PTSD, animal behavioral models of defensive aggression, and neurophysiology of memory, context, theta rhythm, and synaptic transmission in the following paradigm. A PTSD model in the rat is first generated in a learned helplessness paradigm [123], or a social defeat paradigm [124]. The PTSD model rat is then tested in the resident-intruder paradigm [23] for escalation of aggressiveness relative to control rats. The next step is to record theta synchrony and two theta burst-generated long-term synaptic potentiation between the candidate brain structures of aggression (Figure 1) leading up to and during aggression in the resident-intruder paradigm. An increase in synchrony or potentiation during aggression relative to quiescence, and in PTSD aggression relative to control interaction, is indicative of interaction of those brain structures in PTSD-escalated aggression. Finally, and especially in pursuit of pharmacotherapy for aggression in PTSD, G protein-receptor-coupled reagents are tested for their effect in the resident-intruder paradigm on aggressive behavior and on theta coupling and synaptic potentiation between structures in the neuronal system determined in the previous step.

An example of the level of simplification of the brain that we would hope to attain to aid our understanding is a sample-and-hold register as diagrammed in Figure 6.

Information, somehow encoded in a high-frequency burst of action potentials entering from the bottom, is held in the register by serotonergic (5-HT)-induced synaptic potentiation. The system is strobed at theta frequency. For instance, each theta cycle may bring serotonergic activation which would hold the information in the register, or noradrenergic activation, which is evidenced to cancel synaptic potentiation, i.e., erase the information. Alternatively, information may arrive with each theta cycle and be held or passed depending on the serotonergic or adrenergic modulation. The 200 millisecond bins in which visual information enter perception corresponds to the theta frequency centering on $5 \mathrm{~Hz}$

In the context of aggression, an information processing system build from units such as diagrammed in Figure 6 might connect memory and action, and, particularly in PTSD, lay out the manner in which an experience and its context may be fixed in memory and

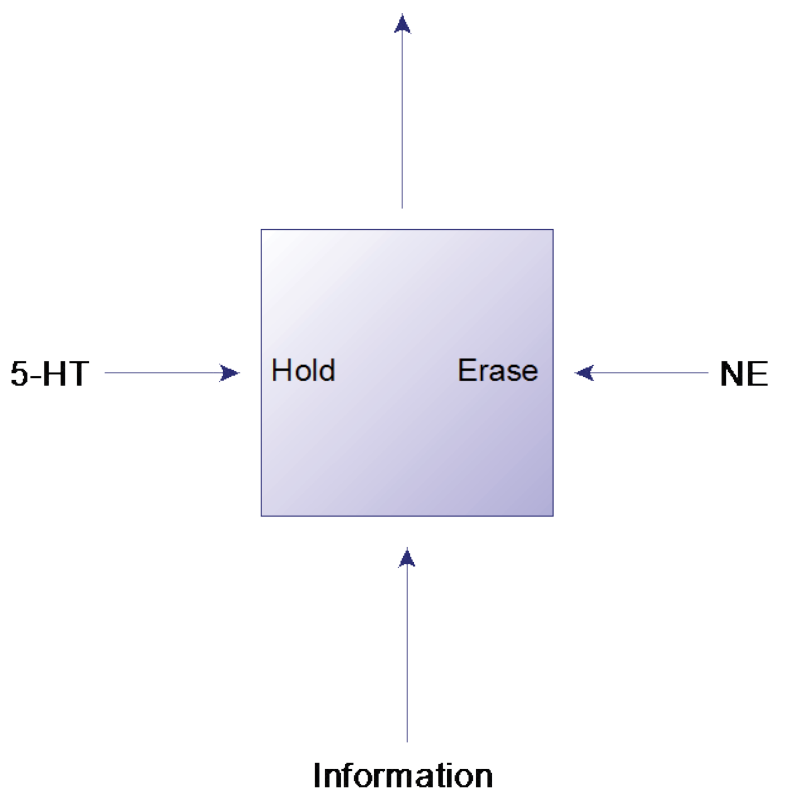

Figure 6: An information processing unit in the brain modeled as a sample-and-hold register. 


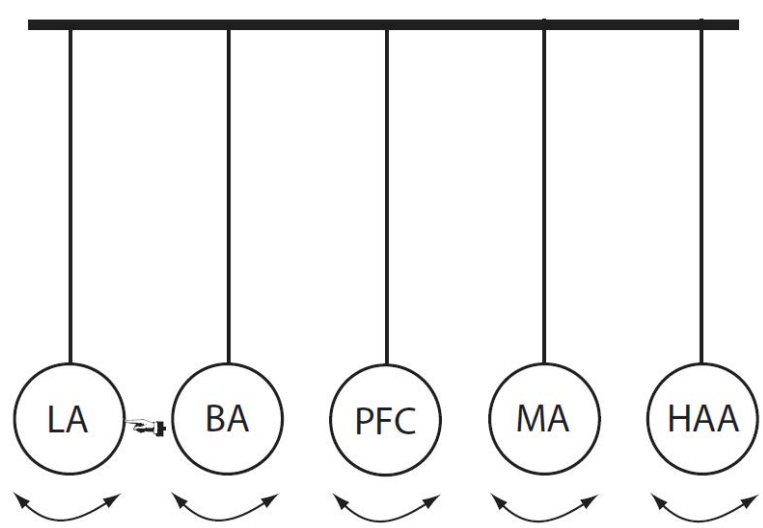

Figure 7: Newton's Cradle.

become metastatic in the psyche. In so far as digital computers are built up of strobed units such as sample and hold registers, principles of information technology may be brought to bear on the issue. Furthermore, a biological system built up as such is inherently nonlinear, meaning that areas of contemporary mathematics such as sensitive dependence on initial conditions and state divergence [125], which in a way model out-of-context behavior, such as inappropriate anger and aggression, might be understood.

\section{Future Directions}

Figure 1 "Neuronal structures involved in aggression, and their connectivity", illustrates that the neurophysiology of aggression can only be understood as the simultaneous interaction of multiple brain regions (Figure 7). Synchrony between the oscillation of the neuronal population field potential of different brain regions may be pursued as an indicator of synaptic interaction between those brain regions.

Some simplification and intuition maybe derived from modeling rhythmic interaction between brain regions as a "Newton's cradle". A Newton's cradle is simply five adjacent steel balls, each hanging on a string.

It is available as an actionable toy on the web or in extended form in science museums such as the San Francisco Exploratorium. When graphed out over time, the oscillation of a ball swinging on a string can be used to model a brain wave. Because this toy is our model for the nuclei of the rat's brain, or yours or mine, we label the balls LA, PFC, R $\triangle$ MA, and HAA, as in figure legend 1 . When you push one ball back ( - ) in our toy brain, say LA, and let it go to hit BA, BA will then swing to hit PFC. PFC will hit MA and MA HAA. String length determines frequency of oscillation. Separation between balls determines how much energy is stored as potential energy before one ball hits the next and how much remains as kinetic energy to be transferred to the next ball. In this toy brain, kinetic energy is synaptic transmission and potential energy is synaptic potentiation.

Peaks and troughs in a multidimensional phase diagram drawn from the multi-nuclei electrode recording would then indicate synaptic interaction between the brain structures involved in aggression. The parameters of a digital model of Newton's cradle (string length for frequency, kinetic energy for synaptic transmission, and potential energy for synaptic potentiation) might be adjusted to give an output matching the multidimensional phase diagram drawn from the multinuclei electrode recording. The adjusted model would then be the model of neuronal interaction during aggression.

Finally, toward understanding aggressiveness in PTSD, the stressed rat is to be compared with the unstressed (control) rat. The parametric differences between the two states are to tell the story.

\section{Acknowledgment}

This work was supported, in part, by the Center for the Study of Traumatic Stress and CDMRP grants W81XWH-08-2-006 as well as W81XWH-08-02-0568 to He Li at USUHS.

\section{References}

1. Benedek DM (2011) Posttraumatic stress disorder from Vietnam to today: The evolution of understanding during Eugene Brody's tenure at the Journal of Nervous and Mental Disease. J Nerv Ment Dis 199: 544-552.

2. Worthen M, Rathod SD, Cohen G, Sampson L, Ursano R, et al. (2014) Anger problems and posttraumatic stress disorder in male and female National Guard and Reserve Service members. J Psychiatr Res 55: 52-58.

3. Kulkarni M, Porter KE, Rauch SA (2012) Anger, dissociation, and PTSD among male veterans entering into PTSD treatment. J Anxiety Disord 26: 271-278.

4. Teten AL, Miller LA, Stanford MS, Petersen NJ, Bailey SD, et al. (2010) Characterizing aggression and its association to anger and hostility among male veterans with post-traumatic stress disorder. Mil Med 175: 405-410.

5. Jakupcak M, Conybeare D, Phelps L, Hunt S, Holmes HA, et al. (2007) Anger hostility, and aggression among Iraq and Afghanistan War veterans reporting PTSD and subthreshold PTSD. J Trauma Stress 20: 945-954.

6. McFall ME, Wright PW, Donovan DM, Raskind M (1999) Multidimensional assessment of anger in Vietnam veterans with posttraumatic stress disorder. Compr Psychiatry 40: 216-220.

7. Beckham JC, Feldman ME, Kirby AC (1998) Atrocities exposure in Vietnam combat veterans with chronic posttraumatic stress disorder: relationship to combat exposure, symptom severity, guilt, and interpersonal violence. J Trauma Stress 11: 777-785.

8. Lasko NB, Gurvits TV, Kuhne AA, Orr SP, Pitman RK (1994) Aggression and its correlates in Vietnam veterans with and without chronic posttraumatic stress disorder. Compr Psychiatry 35: 373-381.

9. Orth U, Wieland E (2006) Anger, hostility, and posttraumatic stress disorder in trauma-exposed adults: a meta-analysis. J Consult Clin Psychol 74: 698-706.

10. Jordan BK, Marmar CR, Fairbank JA, Schlenger WE, Kulka RA, et al. (1992) Problems in families of male Vietnam veterans with posttraumatic stress disorder. J Consult Clin Psychol 60: 916-926.

11. Savarese VW, Suvak MK, King LA, King DW (2001) Relationships among alcohol use, hyperarousal, and marital abuse and violence in Vietnam veterans. J Trauma Stress 14: 717-732.

12. Marshall AD, Panuzio J, Taft CT (2005) Intimate partner violence among military veterans and active duty servicemen. Clin Psychol Rev 25: 862-876.

13. Monson CM, Taft CT, Fredman SJ (2009) Military-related PTSD and intimate relationships: from description to theory-driven research and intervention. Clin Psychol Rev 29: 707-714.

14. Iverson KM, Resick PA, Suvak MK, Walling S, Taft CT (2011) Intimate partner violence exposure predicts PTSD treatment engagement and outcome in cognitive processing therapy. Behav Ther 42: 236-248.

15. Taft CT, Macdonald A, Monson CM, Walling SM, Resick PA, et al. (2013) "Strength at Home" group intervention for military populations engaging in intimate partner violence: pilot findings. J Fam Violence 28: 225-231.

16. Worthen M, Ahern J (2014) The causes, course, and consequences of anger problems in veterans returning to civilian life. J Loss Trauma 19: 355-363.

17. Worthen M, Rathod SD, Cohen G, Sampson L, Ursano R, et al. (2015) Anger and posttraumatic stress disorder symptom severity in a trauma-exposed military population: differences by trauma context and gender. J Trauma Stress 28: $539-546$ 
18. Smith KZ, Smith PH, Violanti JM, Bartone PT, Homish GG (2015) Posttraumatic stress disorder symptom clusters and perpetration of intimate partner violence: findings from a U.S. nationally representative sample. Journal of Traumatic Stress 28:469-474

19. Williston SK, Taft CT, VanHaasteren KO (2015) Military veteran perpetrators of intimate partner violence: challenges and barriers to coordinated intervention. Aggress Violent Beh 21: 55-60.

20. Zaccari B (2015) Domestic violence and intimate partner violence in U.S veterans. International society for traumatic stress studies.

21. Swanson JW, Sampson NA, Petukhova MV, Zaslavsky AM, Appelbaum PS et al. (2015) Guns, impulsive angry behavior, and mental disorders: Results from the National Comorbidity Survey Replication (NCS-R). Behav Sci Law 33:199-212.

22. Tronson NC, Taylor JR (2007) Molecular mechanisms of memory reconsolidation. Nat Rev Neurosci 8: 262-275.

23. Schwabe L, Nader K, Pruessner JC (2014) Reconsolidation of human memory: brain mechanisms and clinical relevance. Biol Psychiatry 76: 274-280.

24. Bard $P$ (1928) A diencephalic mechanism for the expression of rage with special reference to the sympathetic nervous system. Am J Physiol 84: 490-515.

25. Bard P, Mountcastle VB (1948) Suppression And Facilitation Of Angry Behavior By Certain Forebrain Mechanisms. Science 107: 457

26. Fernandez de Molina A, Hunsperger R (1959) Central representation of affective reactions in forebrain and brain stem: Electrical stimulation of amygdala, stria terminalis, and adjacent structures. J Physiol 145: 251-265

27. Fernandez De Molina A, Hunsperger RW (1962) Organization of The Subcortical System Governing Defence And Flight Reactions In The Cat. J Physiol 160: 200-213

28. Egger Md, Flynn JP (1963) Effects Of Electrical Stimulation of The Amygdala on Hypothalamically Elicited Attack Behavior in Cats. J Neurophysiol 26: 705720.

29. Egger MD, Flynn JP (1967) Further studies on the effects of amygdaloid stimulation and ablation on hypothalamically elicited attack behavior in cats. Prog Brain Res 27:165-182

30. Li H, Li X, Smerin SE, Zhang L, Jia M, et al. (2014) Mitochondrial gene expression profiles and metabolic pathways in the amygdala associated with exaggerated fear in an animal model of PTSD. Front Neurol 5: 164.

31. Jia M, Smerin SE, Zhang L, Xing G, Li X, et al. (2015) Corticosterone mitigates the stress response in an animal model of PTSD. J Psychiatr Res 60: 29-39.

32. Blanchard RJ, Blanchard DC, Takahashi T, Kelley MJ (1977) Attack and defensive behaviour in the albino rat. Anim Behav 25: 622-634.

33. Koolhaas JM, Schuurman T, Wiepkema PR (1980) The organization of intraspecific agonistic behaviour in the rat. Prog Neurobiol 15: 247-268.

34. Siegmund A, Wotjak CT (2006) Toward an animal model of posttraumatic stress disorder. Ann N Y Acad Sci 1071: 324-334.

35. Kruk MR, Van der Poel AM, Meelis W, Hermans J, Mostert PG, et al. (1983) Discriminant analysis of the localization of aggression-inducing electrode placements in the hypothalamus of male rats. Brain Res 260: 61-79.

36. Hrabovszky E, Halász J, Meelis W, Kruk MR, Liposits Z, et al. (2005) Neurochemical characterization of hypothalamic neurons involved in attack behavior: glutamatergic dominance and co-expression of thyrotropin-releasing hormone in a subset of glutamatergic neurons. Neuroscience133: 657-666.

37. Bandler R, Keay KA, Floyd N, Price J (2000) Central circuits mediating patterned autonomic activity during active vs. passive emotional coping. Brain Research Bulletin53: 95-104.

38. Kruk MR (1991) Ethology and pharmacology of hypothalamic aggression in the rat. Neurosci Biobehav Rev 15: 527-538.

39. Veenema AH, Neumann ID (2007) Neurobiological mechanisms of aggression and stress coping: a comparative study in mouse and rat selection lines. Brain Behav Evol 70: 274-285.

40. Toth M, Fuzesi T, Halasz J, Tulogdi A, Haller J (2010) Neural inputs of the hypothalamic "aggression area" in the rat. Behav Brain Res 215: 7-20.

41. Canteras NS, Simerly RB, Swanson LW (1995) Organization of projections from the medial nucleus of the amygdala: a PHAL study in the rat. J Comp
Neurol 360: 213-245.

42. Lammers JH, Kruk MR, Meelis W, van der Poel AM (1988) Hypothalamic substrates for brain stimulation-induced attack, teeth-chattering and social grooming in the rat. Brain Res 449: 311-327.

43. Konoshenko MY, Timoshenko TV, Plyusnina IZ (2013) c-Fos activation and intermale aggression in rats selected for behavior toward humans. Behav Brain Res 237: 103-106.

44. Wang Y, He Z, Zhao C, Li L (2013) Medial amygdala lesions modify aggressive behavior and immediate early gene expression in oxytocin and vasopressin neurons during intermale exposure. Behav Brain Res 245: 42-49.

45. Bian X, Yanagawa Y, Chen WR, Luo M (2008) Cortical-like functional organization of the pheromone-processing circuits in the medial amygdala. $J$ Neurophysiol 99: 77-86.

46. Kemble ED, Blanchard DC, Blanchard RJ, Takushi R (1984) Taming in wild rats following medial amygdaloid lesions. Physiol Behav 32: 131-134.

47. Hong W, Kim DW, Anderson DJ (2014) Antagonistic control of social versus repetitive self-grooming behaviors by separable amygdala neuronal subsets. Cell 158: 1348-1361.

48. Dong HW, Petrovich GD, Swanson LW (2001) Topography of projections from amygdala to bed nuclei of the stria terminalis. Brain Res Rev 38: 192-246.

49. Dong HW, Swanson LW (2004) Projections from bed nuclei of the stria terminalis, posterior division: implications for cerebral hemisphere regulation of defensive and reproductive behaviors. J Comp Neurol 471: 396-433.

50. Blume HW, Pittman QJ, Lafontaine S, Renaud LP (1982) Lateral septummedial hypothalamic connections: an electrophysiological study in the rat Neuroscience 7: 2783-2792.

51. Brayley KN, Albert DJ (1977) Suppression of VMH-lesion-induced reactivity and aggressiveness in the rat by stimulation of lateral septum, but not media septum or cingulate cortex. J Comp Physiol Psychol 91: 290-299.

52. Luiten PG, Koolhaas JM, de Boer S, Koopmans SJ (1985) The cortico-medial amygdala in the central nervous system organization of agonistic behavior. Brain Res 332: 283-297.

53. Canteras NS, Simerly RB, Swanson LW (1992) Connections of the posterior nucleus of the amygdala. J Comp Neurol 324: 143-179.

54. Miczek KA, Brykczynski T, Grossman SP (1974) Differential effects of lesions in amygdala,periamygdaloid cortex or stria terminalis on aggressive behavior in rats. J Comp Physiol Psychol 87: 760-771.

55. Tye KM, Prakash R, Kim SY, Fenno LE, Grosenick L, et al. (2011) Amygdala circuitry mediating reversible and bidirectional control of anxiety. Nature 471 : 358-362.

56. Rogan MT, LeDoux JE (1995) LTP is accompanied by commensurate enhancement of auditory-evoked responses in a fear conditioning circuit. Neuron 15: 127-136.

57. Rogan MT, Stäubli UV, LeDoux JE (1997) Fear conditioning induces associative long-term potentiation in the amygdala. Nature 390: 604-607.

58. McKernan MG, Shinnick-Gallagher P (1997) Fear conditioning induces a lasting potentiation of synaptic currents in vitro. Nature 390: 607-611.

59. Eichenbaum H, Otto T, Cohen NJ (1992) The hippocampus--what does it do? Behav Neural Biol 57: 2-36.

60. Morgan B, Terburg D, Thornton HB, Stein DJ, van Honk J (2012) Paradoxical facilitation of working memory after basolateral amygdala damage. PLoS One 7: e38116.

61. Squire LR (1992) Memory and the Hippocampus: A synthesis from findings with rats, monkeys, and humans. Psychol Rev 99: 195-231.

62. Kim JJ, Koo JW, Lee HJ, Han JS (2005) Amygdala inactivation blocks stressinduced impairments in hippocampal long-term potentiation and spatial memory. J Neurosci 25: 1532-1539.

63. LeDoux J (2003) The emotional brain, fear, and the amygdala. Cell Mol Neurobiol 23: 727-738.

64. Debiec J, LeDoux JE, Nader K (2002) Cellular and systems reconsolidation in the hippocampus. Neuron 36: 527-538.

65. Garfinkel SN, Abelson JL, King AP, Sripada RK, Wang X, Gaines LM, et al. 
(2014) Impaired contextual modulation of memories in PTSD: An FMRI and psychophysiological study of extinction retention and fear renewal. J Neurosci 34: 13435-13443.

66. O'Keefe $\mathrm{J}$ (2006) Hippocampal neurophysiology in the behaving animal. In Andersen P, Morris R, Amaral D, Bliss T, O'Keefe J (eds), The Hippocampus Book. Oxford University Press, UK.

67. McNaughton BL, Battaglia FP, Jensen O, Moser El, Moser MB (2006) Path integration and the neural basis of the 'cognitive map'. Nat Rev Neurosci 7 : 663-678.

68. Moser El, Moser MB (2008) A metric for space. Hippocampus 18: 1142-1156.

69. Gothard KM, Skaggs WE, McNaughton BL (1996) Dynamics of mismatch correction in the hippocampal ensemble code for space: interaction between path integration and environmental cues. J Neurosci 16: 8027-8040.

70. Green JD, Arduini AA (1954) Hippocampal Electrical Activity In Arousal. J Neurophysiol 17: 533-557.

71. Buzsáki G1 (2002) Theta oscillations in the hippocampus. Neuron 33: 325-340

72. Mitchell SJ, Ranck JB Jr (1980) Generation of theta rhythm in medial entorhinal cortex of freely moving rats. Brain Res 189: 49-66.

73. Paré D, Gaudreau H (1996) Projection cells and interneurons of the lateral and basolateral amygdala: distinct firing patterns and differential relation to theta and delta rhythms in conscious cats. J Neurosci 16: 3334-3350.

74. Stewart M, Fox SE (1990) Do septal neurons pace the hippocampal theta rhythm? Trends Neurosci 13: 163-168.

75. Vanderwolf, C H (1988) Dorsal raphé nucleus serotonergic projection to hippocampus generates theta rhythm. Int Rev Neurobiol 30, 225-340.

76. Kirk IJ (1998) Frequency modulation of hippocampal theta by the supramammillary nucleus, and other hypothalamo-hippocampal interactions: mechanisms and functional implications. Neurosci Biobehav Rev 22: 291-302.

77. Vertes RP (1981) An analysis of ascending brain stem systems involved in hippocampal synchronization and desynchronization. J Neurophysiol 46: 11401159.

78. Nuñez A, de Andrés I, García-Austt E (1991) Relationships of nucleus reticularis pontis oralis neuronal discharge with sensory and carbachol evoked hippocampal theta rhythm. Exp Brain Res 87: 303-308

79. O'Keefe J, Recce ML (1993) Phase relationship between hippocampal place units and the EEG theta rhythm. Hippocampus 3: 317-330.

80. Hafting T, Fyhn M, Bonnevie T, Moser MB, Moser El (2008) Hippocampusindependent phase precession in entorhinal grid cells. Nature 453: 1248-1252.

81. Jezek K, Henriksen EJ, Treves A, Moser El, Moser MB (2011) Theta-paced flickering between place-cell maps in the hippocampus. Nature 478: 246-249.

82. Winson J (1978) Loss of hippocampal theta rhythm results in spatial memory deficit in the rat. Science 201: 160-163.

83. Adhikari A, Topiwala MA, Gordon JA (2010) Synchronized activity between the ventral hippocampus and the medial prefrontal cortex during anxiety. Neuron 65: 257-69.

84. Colgin LL, Denninger T, Fyhn M, Hafting T, Bonnevie T, et al. (2009) Frequency of gamma oscillations routes flow of information in the hippocampus. Nature 462: 353-357.

85. Rudell AP, Fox SE, Ranck JB Jr (1980) Hippocampal excitability phase-locked to the theta rhythm in walking rats. Exp Neurol 68: 87-96.

86. Larson J, Wong D, Lynch G (1986) Patterned stimulation at the theta frequency is optimal for the induction of hippocampal long-term potentiation. Brain Res 368: $347-350$.

87. Hyman JM, Wyble BP, Goyal V, Rossi CA, Hasselmo ME (2003) Stimulation in hippocampal region $\mathrm{CA} 1$ in behaving rats yields long-term potentiation when delivered to the peak of theta and long-term depression when delivered to the trough. J Neurosci 23:11725-11731.

88. Pavlides C, Greenstein YJ, Grudman M, Winson J (1988) Long-term potentiation in the dentate gyrus is induced preferentially on the positive phase of theta rhythm. Brain Res 439: 383-387.

89. Kocsis B, Vertes RP (1992) Dorsal raphe neurons: synchronous discharge with the theta rhythm of the hippocampus in the freely behaving rat. J Neurophysio
68: $1463-1467$

90. Chen AQ, Chen XC, Zhou RX, Wang W (2008) [Involvement of protein kinase $\mathrm{C}$ in NMDAR-dependent long-term potentiation in rat amygdala.]. Sheng Li Xue Bao 60: 737-742.

91. Maren S, Fanselow MS (1995) Synaptic plasticity in the basolateral amygdala induced by hippocampal formation stimulation in vivo. J Neurosci 15: 7548 7564.

92. Jiang X, Chen A, Smerin S, Zhang L, Li H (2011) Pharmacology of 5-HT2 modulation of amygdala and hypothalamus in anxiety disorders, Chapter $3, \mathrm{pp}$. 39-50 in Anxiety Disorders, Intech, Croatia, 2011)

93. Miczek KA, de Almeida RM, Kravitz EA, Rissman EF, de Boer SF, et al. (2007) Neurobiology of escalated aggression and violence. J Neurosci 27: 1180311806.

94. Kulikov AV, Osipova DV, Naumenko VS, Terenina E, Mormède P, et al. (2012) A pharmacological evidence of positive association between mouse intermale aggression and brain serotonin metabolism. Behav Brain Res 233: 113-119.

95. Takahashi A, Shimamoto A, Boyson CO, DeBold JF, Miczek KA (2010) $\mathrm{GABA}(\mathrm{B})$ receptor modulation of serotonin neurons in the dorsal raphé nucleus and escalation of aggression in mice. J Neurosci 30: 11771-11780.

96. Popova NK, Naumenko VS, Plyusnina IZ, Kulikov AV (2005) Reduction in 5-HT1A receptor density, 5-HT1A mRNA expression, and functional correlates for 5 -HT1A receptors in genetically defined aggressive rats. J Neurosci Res 80: $286-292$

97. Naumenko EV, Popova NK, Nikulina EM, Dygalo NN, Shishkina GT, et al (1989) Behavior, adrenocortical activity, and brain monoamines in Norway rats selected for reduced aggressiveness towards man. Pharmacol Biochem Behav 33: 85-91.

98. Jiang X, Zhang ZJ, Zhang S, Gamble EH, Jia M, et al. (2011) 5-HT2A receptor antagonism by MDL 11,939 during inescapable stress prevents subsequent exaggeration of acoustic startle response and reduced body weight in rats. J Psychopharmacol 25: 289-297.

99. Takahashi A, Kwa C, Debold JF, Miczek KA (2010) GABA(A) receptors in the dorsal raphé nucleus of mice: escalation of aggression after alcohol consumption. Psychopharmacology (Berl) 211: 467-477.

100. Takahashi A, Lee RX2, Iwasato T3, Itohara S4, Arima H5, et al. (2015) Glutamate input in the dorsal raphe nucleus as a determinant of escalated aggression in male mice. J Neurosci 35: 6452-6463.

101. Jiang X, Xing G, Yang C, Verma A, Zhang L, et al. (2009) Stress impairs 5-HT2A receptor mediated serotonergic facilitation of GABA release in juvenile rat basolateral amygdala. Neuropsychopharmacology 34: 410-423.

102. Li H, Zhang L, Chen A, Jiang X, Gamble E, et al. (2009) Stress impairs 5- HT2 receptor-mediated facilitation of neuroplasticity in the basolateral amygdala. Society for Neuroscience abstract 250: 15.

103. Warden MR, Selimbeyoglu A, Mirzabekov JJ, Lo M, Thompson KR, et al. (2012) A prefrontal cortex-brainstem neuronal projection that controls response to behavioural challenge. Nature 492: 428-432.

104. Zubieta JK, Chinitz JA, Lombardi U, Fig LM, Cameron OG, et al. (1999) Medial frontal cortex involvement in PTSD symptoms: a SPECT study. J Psychiatr Res 33: 259-264.

105. Manion ST, Gamble EH, Li H (2007) Prazosin administered prior to inescapable stressor blocks subsequent exaggeration of acoustic startle response in rats. Pharmacol Biochem Behav 86: 559-565.

106. Braga MF Aroniadou-Anderjaska V Manion ST, Hough CJ, LiH(2004) Stress impair a1A adrenoceptor-mediated noradrenergic facilitation of GABAergic transmission in the basolateral amygdala. Neuropsychopharmacology 29: 45-58.

107. Stein DJ, Pedersen R, Rothbaum BO, Baldwin DS, Ahmed S, et al. (2009) Onset of activity and time to response on individual CAPS-SX17 items in patients treated for post-traumatic stress disorder with venlafaxine ER: a pooled analysis. Int Neuropsychopharmacol 12: 23-31.

108. Davidson J, Stein DJ, Rothbaum BO, Pedersen R, Szumski A, et al. (2012) Resilience as a predictor of treatment response in patients with posttraumatic stress disorder treated with venlafaxine extended release or placebo. J Psychopharmacol 26: 778783.

109. Vertes RP, Kinney GG, Kocsis B, Fortin WJ (1994) Pharmacological suppression of the median raphé nucleus with serotonin1A agonists 8-OH-DPAT and buspirone, produces hippocampal theta rhythm in the rat. Neuroscience 60: 441-451. 
Citation: Smerin SE, Chen A, Li H (2016) Neurophysiology of Aggression in Posttraumatic Stress Disorder. J Psychiatry 19: 364 doi:10.4172/2378-5756.1000364

Page 11 of 11

110. Chen A, Hough CJ, Li H (2003) Serotonin type II receptor activation facilitates synaptic plasticity via $\mathrm{N}$-methyl-D-aspartate-mediated mechanism in the rat basolateral amygdala. Neuroscience 119:53-63.

111. Egorov AV, Unsicker K, von Bohlen und Halbach O (2006) Muscarinic control of graded persistent activity in lateral amygdala neurons. Eur J Neurosci 24: 31833194

112. Glasgow SD, Glovaci I, Karpowicz LS, Chapman CA (2012) Cholinergic suppression of excitatory synaptic transmission in layers II/III of the parasubiculum. Neuroscience 201: 1-11.

113. Jayanthi S, Kang SW, Bingham D, Tessaro BA, Suresh Kumar TK, et al. (2014) Identification of antagonists to the vasotocin receptor sub-type 4 (VT4R) involved in stress by molecular modelling and verification using anterior pituitary cells. $J$ Biomol Struct Dyn 32: 648-660.

114. Veenema AH, Beiderbeck DI, Lukas M, Neumann ID (2010) Distinct correlations of vasopressin release within the lateral septum and the bed nucleus of the stria terminalis with the display of intermale aggression. Horm Behav 58:273-281.

115. Young WS, Li J, Wersinger SR, Palkovits $M(2006)$ The vasopressin $1 \mathrm{~b}$ receptor is prominent in the hippocampal area CA2 where it is unaffected by restraint stress or adrenalectomy. Neuroscience 143: 1031-1039.

116. Federico P, Malkinson TJ, Cooper KE, Pittman QJ, Veale WL (1992) Vasopressin perfusion within the medial amygdaloid nucleus attenuates prostaglandin fever in the urethane-anesthetized rat. Brain Res 587: 319-326.

117. Bergado JA, Frey S, López J, Almaguer-Melian W, Frey JU (2007) Cholinergic afferents to the locus coeruleus and noradrenergic afferents to the medial septummediate LTP-reinforcement in the dentate gyrus by stimulation of the amygdala. Neurobiology. Neurobiol Learn Mem 88: 331-341.

\section{Add Gene Database}

119. Daskalakis NP, Cohen H, Cai G, Buxbaum JD, Yehuda R (2014) Expression profiling associates blood and brain glucocorticoid receptor signaling with traumarelated individual differences in both sexes. Proc Natl Acad Sci USA 111:1352913534.

120. Muhie S, Gautam A, Meyerhoff J, Chakraborty N, Hammamieh R, et al. (2015) Brain transcriptome profiles in mouse model simulating features of post-traumatic stress disorder. Mol Brain 8:14-21.

121. Otto T, Eichenbaum H, Wiener SI, Wible CG (1991) Learning-related patterns of CA1 spike trains parallel stimulation parameter optimal for inducing hippocampal long-term potentiation. Hippocampus 1:181-192.

122. Francesconi W, Berton F, Koob GF, Sanna PP (2009) Intrinsic neuronal plasticity in the juxtacapsular nucleus of the bed nuclei of the stria terminalis (jcBNST). Prog Neuropsychopharmacol Biol Psychiatry 33: 1347-1355.

123. Ottenweller JE, Natelson BH, Pitman DL, Drastal SD ( 1989) Adrenocortical and behavioral responses to repeated stressors: Toward an animal model of chronic stress and stress-related mental illness. Biol Psychiatry 26: 829-841.

124. Meerlo P, Overkamp GJ, Koolhaas JM (1997) Behavioural and physiological consequences of a single social defeat in Roman high- and low-avoidance rats. Psychoneuroendocrinology 22: 155-168.

125. Fan YS, Chay TR (1995) Crisis and topological entropy. Phys Rev E Stat Phys Plasmas Fluids Relat Interdiscip Topics 51: 1012-1019. 